\title{
Research on the Tourism Development and Countermeasures of Nishan Town -Based on SWOT Analysis
}

\author{
Zihan Yan, Xiujuan Wang* \\ School of Public Administration, Shandong Agricultural University, Tai'an, China \\ Email: yanzihan1104@163.com, *xjw9007@126.com
}

How to cite this paper: Yan, Z. H., \& Wang, X. J. (2021). Research on the Tourism Development and Countermeasures of Nishan Town-Based on SWOT Analysis. Journal of Service Science and Management, 14, 429-443.

https://doi.org/10.4236/jssm.2021.144027

Received: April 27, 2021

Accepted: July 31, 2021

Published: August 3, 2021

Copyright $\odot 2021$ by author(s) and Scientific Research Publishing Inc. This work is licensed under the Creative Commons Attribution International License (CC BY 4.0).

http://creativecommons.org/licenses/by/4.0/ (c) (i) Open Access

\begin{abstract}
As an important measure of rural development, rural tourism plays an essential role in rural revitalization. Located in the birthplace of the founder of the Confucian School, Nishan Town has significant advantages in cultural tourism. In recent years, Nishan Town has developed rapidly and has been selected as one of the top 100 characteristic towns in the country in 2020. Although the development of Nishan Town has many advantages, it also faces severe challenges. Based on field investigations, this article conducts the method of SWOT analysis in the development of Nishan Town's tourism industry. Result shows that Nishan Town's resources and location are richly endowed by nature; taking the opportunity to hold the CCTV Mid-Autumn Festival main venue, it has grown quickly. However, the low quality of workers and fierce competition have restricted the development of Nishan Town. According to the growth, reversal, avoidance and defensive strategies analyzed by SWOT, this article proposes countermeasures in order to provide a reference for the development of tourism in Nishan Town.
\end{abstract}

\section{Keywords}

SWOT Analysis, Nishan Town, Tourism, Development, Countermeasures

\section{Introduction}

In 2017, the rural revitalization strategy was first proposed in the report of the 19th National Congress of the Communist Party of China. Listed as one of the "seven major strategies" for the future development of the party and the country (Liu, 2020), the rural revitalization strategy is the core and key issue of country's national development (Kong \& Zheng, 2010). The country will prosper if the rural areas are prosperous, and the country will decline if rural areas are declin- 
ing (Liao, 2019). The implementation of the rural revitalization strategy is related to the resolution of the main social contradictions in the new era of country (Liu, Jia, \& Zhang, 2020), and to whether our country can fundamentally solve the problems of urban-rural differences and insufficient rural development (Li, Zhu, Wang, Tao, \& Tao, 2020). Since then, documents related to rural revitalization have been released one after another (Gan, Gao, \& Li, 2021), such as the "Strategic Plan for Rural Revitalization (2018-2022)" issued by the Central Committee of the Communist Party of China and the State Council in 2018, and "No.1 central document" for 2021, "Opinions of the Central Committee of the Communist Party of China and State Council on comprehensively pushing forward rural vitalization and accelerating the modernization of agriculture and rural areas". On February 25, 2021, the National Administration for Rural Revitalization was formally inaugurated. Rural tourism is a new type of tourism business activity which takes rural areas as places and relies on the environment, rural landscape, folk culture and other resources of the rural areas to provide tourists with leisure, sightseeing, vacation, experience, shopping, and entertainment and many other services. The development of rural tourism can create a new income point for rural areas, but also help the improvement construction of local infrastructure and the protection of natural ecology (Li, 2021). At present, rural tourism has not been clearly defined, but the core view is basically that urban tourists (surrounding areas), as the main consumers, come to nearby rural areas for sightseeing or seeking leisure and entertainment experiences. As important ways of rural revitalization, rural tourism and characteristic towns not only meet the needs of rural economic development and environmental protection, but also tourists for leisure, seeking knowledge and returning to nature, which have got more and more attention and have made a significant contribution.

Nishan Town is located in the southeast of Qufu, Shandong Province. It borders Tianhuang Town and Dashu Town in Zoucheng in the southeast, Xizhu Town in the west, Fangshan Town in the north, and Shengshuiyu Town in Sishui in the northeast. The People's Government of town is 15 kilometers away from the urban area of Qufu, with a total area of 101.09 square kilometers. In 2010, the Nishan Provincial Cultural Tourism and Resorts Zone was established. In 2020, it was selected as one of the top 100 characteristic towns in the country. In 2021, it was selected as the first batch of characteristic towns in Shandong Province. Nishan Town is the birthplace of Confucius, the founder of the Confucian school, which enjoys unique resource and location advantages. The launch of the CCTV Mid-Autumn Festival main venue in the Nishan Holy Land and the completion of the traffic hub of Qufu East Railway Station have brought great opportunities to the growth of Nisan Town. However, with the rapid development of tourism in Nishan Town, the challenges faced by Nishan Town cannot be ignored. The phenomenon of homogenization of the same type of scenic spots is serious, the competition is fierce, and with the development of the times, people's concept of tourism has changed. In the face of many challenges, Nishan Town's development strategy is crucial. 


\section{SWOT Analysis on Tourism in Nishan Town}

SWOT analysis is Superiority Weakness Opportunity Threats. The four letters of SWOT respectively represent: $\mathrm{S}$ is strengths, $\mathrm{W}$ is weaknesses, $\mathrm{O}$ is opportunities, and T is threats. Since the 1990s, the SWOT analysis has gradually been applied to the field of tourism planning, providing a strategic basis for the analysis and evaluation of the comprehensive competitiveness and the formulation of development goals and plans of tourism destinations. This article analyzes the internal and external environment of Nishan Town from four aspects and proposes development strategies.

\subsection{Strengths Analysis}

\subsubsection{Resource Strengths}

Nishan Town is the birthplace of Confucius, the founder of Confucianism, which is rich in cultural and tourist resources, mainly including Nishan Confucian Temple and Confucius Cave, and the traditional elements are well-preserved. As Nishan Town was selected as a national characteristic town and a provincial characteristic town, its publicity was improved rapidly. The Huangtu village has established Nishan Holy Land, which is functionally positioned as a "sacred place for cultural cultivation of talents" and "world-class humanistic tourism destination". In 2020, Luyuan New Village was selected as a key rural tourism village in the province and one of the province's 100 beautiful streets and lanes. The establishment of high-end hotels and guest houses such as Nishan Inn, Nishan Academy, etc., helped Nishan Town to build a tourism complex. Nishan Town has superior climatic conditions, with beautiful natural environments such as Nishan and Confucius Lake. Due to the fertile soil, abundant water resources and superior crop planting conditions, Nishan Town has carried out farmhouse picking activities such as apples and peaches.

Qufu, where Nishan Town is located, is one of the birthplaces of ancient Chinese culture, with a history of more than 5000 years. Shouqiu near the Shaohao Mausoleum in the east of Qufu is the birthplace of the Yellow Emperor in the legend, where now has the tomb of the Yellow Emperor's son Shaohao and the Jingling Palace site built for the Yellow Emperor in the Song Dynasty. Among three sovereigns and five emperors in ancient China, four people have left traces of activities in Qufu, and three of them were scheduled to be here. The civilization history of nearly two thousand years has made Qufu one of the most important political and cultural centers in ancient China. Qufu is rich in cultural resources and is an ancient capital of oriental culture. According to statistics, Qufu currently has more than 300 cultural relics and historic sites including the World Cultural Heritage "Three Confucius" with more than 5000 ancient stone tablet inscriptions, and it is the place with the largest concentration of inscriptions in Han Dynasty in China, including more than 300,000 archives in the Ming and Qing Dynasties and more than one hundred thousand cultural relics in their collections. "Three holes, two cities and four mountains" embodies the three rich cultural resources of Qufu: Confucian culture, Yanhuang culture and Lu culture. 
The Confucian Temple, Confucian Mansion, and Confucian Forest have been included in the "World Cultural Heritage List" by UNESCO, and the ruins of the ancient city of Lu are known as the "Oriental Underground Museum".

Nishan Town has a low degree of industrial development with no large-scale industrial factories in the area, scattered with small-scale quarrying and mining, etc.. The air quality is excellent, and there is a large-scale reservoir in the area, Nishan Reservoir, which provides a strong guarantee for ecological water supply in the surrounding area. The total forest-cover rate reaches $17 \%$ on average. The dense distributed forests around the reservoir area are natural negative ion oxygen bars, which were awarded the title of National Wetland Park in 2008, therefore, such a powerful geographical environment has become a good place for people around to spend their leisure time.

\subsubsection{Location Strength}

Nishan Town is located at the border of Qufu, Sishui and Zoucheng town, which is convenient to strengthen the connection with surrounding counties and cities. Relying on Nishan and Confucius Lake, Nishan Town has formed a regional landscape "one mountain, one water area and one sage". The location of Nishan Town is shown in Figure 1. The latecomer advantage of the town is complementary to the advantages of the old scenic spots such as Sankong. At the same time, the tourism industry of Nishan Town, which belongs to Qufu, is developed, and together with famous tourist attractions such as Mount Tai and Baotu Spring in Shandong province forming the historic and cultural central axis of "one mountain, one water, one sage".

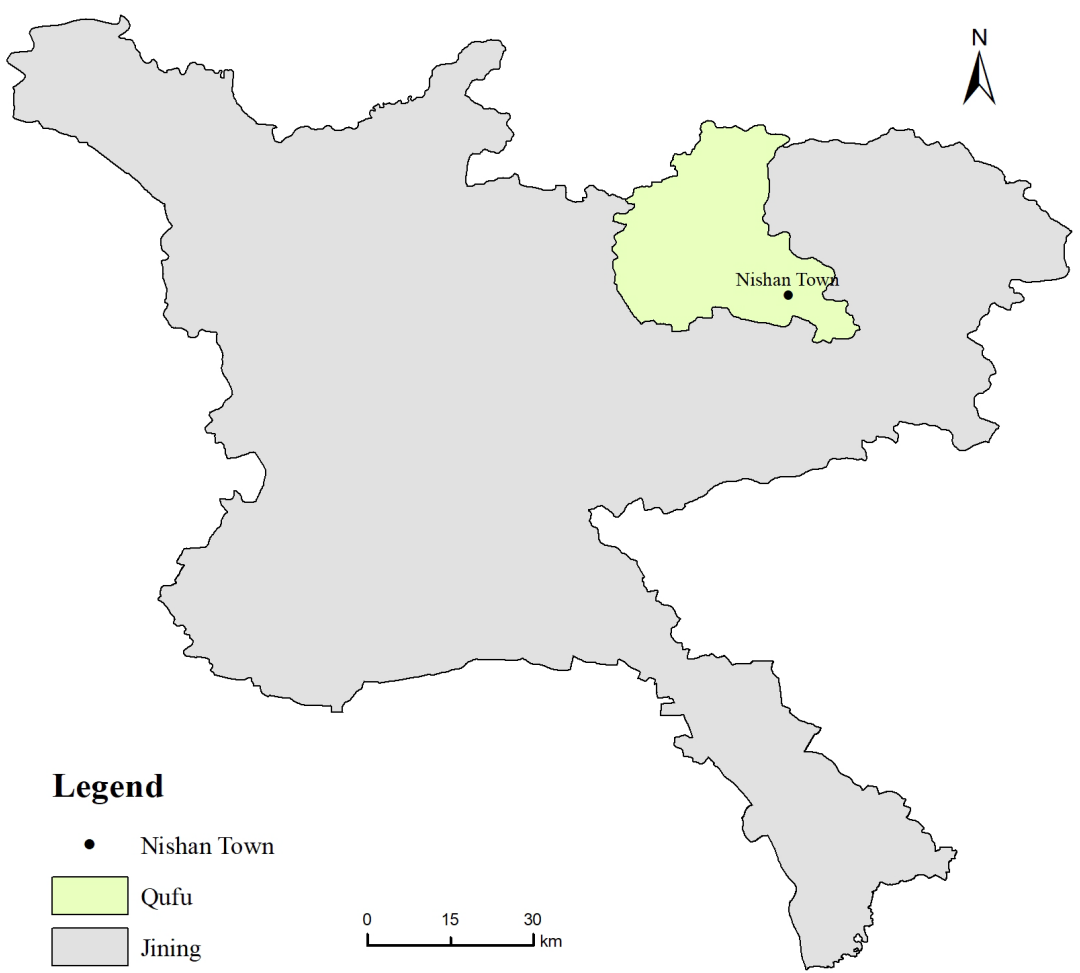

Figure 1. Location of Nishan Town. 
With Nishan Town as the center, it radiates outwards, including Lunan Economic Belt, Jinan Metropolitan Area, Shandong Peninsula Urban Group, etc.. The Beijing-Shanghai high-speed railway makes Qufu more closely connected with the Yangtze River Delta Economic Zone and the Beijing-Tianjin-Hebei Metropolitan Area. Shandong Province, where Qufu is located, and neighboring provinces such as Jiangsu, Henan, Anhui, Hebei, etc., are economically strong or populous provinces, where consumer groups are relatively mature and have a strong interest in cultural tourism.

\subsubsection{Transportation Strength}

Qufu has formed a traffic pattern with dual development of roads and railways, and in future aviation advantages will also be prominent. Jining Qufu Airport was officially completed in 2008. In addition, the new airport in Caohe Town, Yanzhou District is under construction, which is expected to be built in 2025. It will take about half an hour from Qufu East Station to Nishan Town. The completion Beijing-Shanghai High-speed Railway and Lunan High-speed Railway, and the expansion of Qufu East Station has made Qufu an important transportation hub in southwestern Shandong. Qufu East Station will reach Nishan Town in about half an hour. With policy support, Confucius Avenue, the main road leading to Nishan Town in Qufu, has improved road conditions. It takes about forty minutes to reach Nishan Town from the downtown area. There are special lines for the Nishan Holy Land in some landmark buildings and direct buses to Nishan Town in the urban area. A number of roads entering Nishan Town in different directions are under construction and road renovation in Nishan Town, which makes obvious advantage in communications.

\subsubsection{Customer Strength}

Qufu's tourism development started early and has a strong foundation. At the beginning of reform and opening up, it was proposed that tourism should be an important pillar of economic revitalization. Therefore, the early development of tourism has accumulated a considerable amount of tourists for Qufu. In recent years, with the introduction of the slogan "Oriental Holy City, the Best District", the influence of Qufu's tourism brand has been further expanded. The volatility of the tourism market has made tourist sources the key to tourism development. Relying on old scenic spots such as the "Three Confucius", Qufu has accumulated provincial, domestic and international tourist sources, which have laid a solid foundation for the development of tourism in Nishan Town.

\subsubsection{Policy Strengths}

Local government has a high enthusiasm to develop tourism, adopting various measures such as politics, culture, and economy to vigorously support and making tourism planning and tourism forums, which have provided a good macro environment for Qufu's tourism industry. For a long time, Shandong Province has attached great importance to rural tourism, and has established a management system and pattern for the development of rural tourism to support it. 
Rural tourism in Shandong Province started very early, relying on the foundation of being a large agricultural province, it has maintained a momentum of rapid growth for a long time. According to the "Shandong Province Rural Revitalization Strategic Plan (2018-2022)" issued by the Shandong Provincial Party Committee and the Provincial Government, Shandong Province would strive to create a rural tourism model-“Qilu model”, develop 100 rural tourism cluster areas and 300 rural tourism parks by 2020, and achieve rural tourism consumption of 360 billion yuan.

\subsection{Weaknesses Analysis}

\subsubsection{Low Quality of Workers}

The success of the tourism industry largely depends on the high-quality and scientific management of the operators. In recent years, although the tourism market has become standardized and the level of tourism management and operators in Nishan Town has been improved, there is still a widening gap with market demand. In addition, the management system is not perfect with poor function, and the level of law enforcement needing to be improved. Senior management personnel in the tourism industry in Nishan Town have professional mismatches, tourism lacks professionals' scientific planning and management and professionals engaged in tourism product development and planning are rare. Due to the distance from the urban area, it is easy to develop economy and employment in the surrounding villages. But the service personnel employed are mostly farmers in the surrounding villages, with low cultural level, insufficient experience, and lack of professional training, which reduces the tourism experience. Some vendors have developed a stall economy on major traffic roads for personal gain, which affects traffic order and the appearance of the city. The poor tourism mechanism, the low level of operation and management, and the low quality of practitioners have become obstacles restricting the high-quality development of tourism in Nishan Town.

\subsubsection{Difficulty in Urban Transformation}

Affected by the low level of development, the vast majority of residents in $\mathrm{Ni}$ shan Town are farmers, modern agriculture has not yet formed, large-scale agricultural industrial parks have not been established so that residents in the town have low average income, living simple lifestyle with conservative thinking. The rest of the residents are mostly migrant workers, and few return to their hometowns to start their own businesses, failing to drive the transformation of the township model, which has become the main reason for the difficulties in the transformation.

\subsubsection{Insufficient Development}

Although Qufu has formed a traffic pattern in three aspects: roads, railways, and aviation, which has made a significant contribution to the development of tourism in Nishan Town, but there are still some restrictive factors. For instance, 
fewer trains stop in Qufu Railway Station but more in Yanzhou Station. A transit is required to enter Qufu from Yanzhou Station, and it also takes some time from the airport to Nishan Town. Nishan Town is a cultural and tourist sacred place, and the scenic spots are mostly cultural landscapes, which makes the tourism of Nishan Town only in traditionally visiting. At the level, it is difficult to communicate with tourists, and there are fewer experiential projects that can make tourists visit for a long time, which is similar to other traditional landscape tours, weakening the enthusiasm of tourists to a certain extent. Tourists come here mostly for day trips and scenic spots lack attraction so that the shortcomings are serious, which makes the accommodation industry poorly developed. The low occupancy rate of hotels, guesthouses and homestays makes it difficult to bring economic benefits. Because of low tourism agglomeration, poor mechanism, few entertainment projects and shopping places, it is hard to form a tourism complex. The difficulties of scenic spots are unreasonable prices of the homestays and restaurants and poor conditions of security and sanitation. Due to the inadequate management of the environment during the tourism process, the scenic spots are often dirty, messy, and poor, which damages the cultural atmosphere and damages the experience of tourists. The marketing promotion of rural tourism in Shandong Province is mostly based on word-of-mouth promotion, that is, tourists who come here recommend it to relatives and friends. Most companies lack the necessary market awareness and cannot conduct segmented marketing campaigns for different groups. Most of them indulge in the rich local resources and the policy support provided by the provincial government, rarely investing resources to establish a marketing channel system. Inadequate publicity of scenic spots and low website level are also signs of insufficient development.

\subsection{Opportunities Analysis}

\subsubsection{The Impact of Social Activities}

Qufu regularly holds Confucius Cultural Festivals, giving full play to the cultural connotation of Qufu. In 2005, Confucius Cultural Festival Ceremony was broadcast live on CCTV throughout the world, accelerating the development of Qufu's cultural tourism industry. In 2008, Olympic torch was relayed in Qufu and expanded Qufu's international reputation. The holding of the Nishan World Civilization Forum has brought a certain degree of visibility to Nishan Town, bringing into play the cultural heritage of Nishan Town, and building the Nishan World Confucianism Center. The 2018 CCTV Mid-Autumn Festival main venue was held in Nishan Holy Land and the Spring Festival Gala at the venue was set up in Qufu. The holding of the national evening party increased the exposure of Nishan Town. The Nishan Holy Land created large-scale ritual and music performance activity called "Golden Sounds and Jade Vibrations", with the intention of "Confucius in the world, Confucius in the world". The establishment of the Confucius Institute further deepened Qufu's international influence. 


\subsubsection{Socio-Economic Factors}

At present, the concepts of optimizing the industrial structure, transforming the economic development mode, putting people first, reform and opening up, sustainable development and circular economy, etc. have penetrated into all fields of entire social economy, including the modern service industry, which is becoming one of the main boosters of the economy. These macro policies have provided new space and opportunities for the development of rural tourism.

At present, our cities' development presents congestion, fast-paced and serious environmental problems, while in the countryside, the characteristics of rural hollowness, decline and backwardness are obvious. Developing rural tourism has become the best choice to meet the needs of urban leisure and vacation and the revitalization of rural areas. Both supply and demand have great potential. The accumulated tourist sources of Qufu's old-brand tourist attractions such as "Three Confucius" and "Six Arts City" are shared to a certain extent with Nishan Town, which has a late-comer advantage, bringing a rich passenger flow to Nishan Town. The introduction of policies such as the construction of the Lunan Economic Belt, Jinan Metropolitan Circle, Shandong Peninsula City Group, etc., has brought new growth points to the economy, and the coordinated development of regional economies is bound to drive the development of tourism in Nishan Town. There are many high-speed rail lines under construction at Qufu East Station, making Qufu's status as a transportation hub increasingly prominent. The rapid development of the Internet has allowed tourists to book tickets and book accommodation online, reducing ticket congestion, improving tour efficiency, and facilitating tourists' travel. Thanks to the innovation of science and technology, drone performances, musical fountains, and electronic fireworks shows in the Nishan Holy Land are also highlights that attract tourists.

\subsubsection{The Development of Tourism in Shandong Province}

Shandong Province is known as the "State of Qilu" and has nurtured Qilu Culture with profound impact on Chinese culture and even later generations. The agricultural civilization, the Yellow River civilization and other spiritual civilization achievements, as well as the historical sites and cultural works formed from them, are the advantages of Shandong Province's tourism. The North China Plain, where Shandong Province is located, has flat terrain, fertile soil, and sufficient water sources, which is extremely beneficial to agricultural development, making Shandong Province a developed agricultural area. With the development of modern technology and agricultural modernization, Shandong Province has built a number of agricultural science and technology tourism garden. The integration of the traditional farm civilization and modern agricultural technology has formed a bright spot in rural tourism in Shandong Province. In addition, the government continues to increase its support for rural tourism, relying on some cities and counties with rich tourism resources to build characteristic tourist scenic towns and scenic villages, and improve the local tourist infrastructure and 
service system. At the same time, government constructs a mechanism of "multi-party participation and market operation" led by itself and coordinated by various departments to create a good environmental foundation for the development of rural tourism. It is hoped that the leading role of the tourism industry can be brought into play and promote the prosperity of the rural real economy.

\subsection{Threats Analysis}

\subsubsection{Fierce Competition}

With the improvement of people's living standards and conditions, more and more people regard tourism as a way to broaden their horizons, which makes many regions pay more attention to develop tourism, invest a lot of funds to develop resources, and improve existing tourism conditions, therefore, competition between regions is fierce. As an emerging scenic spot, although the infrastructure and other relatively old tourist attractions are competitive, Nishan Town's overall strength is limited and some factors such as insufficient development and publicity restrict its competitive power. Shimenshan Town, another town in Qufu, has brought great competition to the Nishan Town. In recent years, Shimenshan Town has vigorously developed skiing, fruit and vegetable picking and other entertainment projects, attracting a large number of tourists, and Shimenshan Village has been selected as a national key village for rural tourism. The rise of tourism in surrounding cities and rural eco-tours has also put pressure on Nishan Town.

\subsubsection{Changes in the Trend of the Times}

With the changes in people's values, people's attitudes towards tourism are gradually changing, transitioning from traditional visiting styles to experiential styles and leisure styles. The tourism resources of Nishan Town are mostly static landscapes, and the bottleneck of low interaction has not been solved. The development of tourism industry still stays in the traditional visiting style. Tourists come here mostly for day trips so that there are few repeat visitors and the source of tourists is unstable, which has brought a great impact on town's tourism industry. In addition, the cultural and creative products of Nishan tourism lack innovation, making it difficult to attract young people who are the mainstay of tourism.

\subsubsection{Homogenization}

The development of towns and streets across the country has basically entered a period of choosing patterns and paths to grow, but finding a suitable model for their own development is a process of exploration which is not an easy task. The industrial model built around tourism in Nishan Town has many precedents in other areas of Jining, but it still faces great challenges. Like Shimenshan Town in Qufu City, through skiing, picking and other projects, explored a path of economic development.

In summary, according to SWOT analysis, Nishan Town's tourism has obvious advantages, but its own disadvantages also restrict its development. 
Therefore, the development of Nishan Town should give full use of its own advantages, seize opportunities, improve disadvantages, and respond to challenges.

\section{Countermeasures for the Development of Tourism in Nishan Town}

\subsection{SWOT Analysis Framework Diagram}

The SWOT analysis framework of tourism development in Nishan Town is shown in Table 1.

\subsection{Countermeasures for the Development of Tourism in Nishan Town}

\subsubsection{Pay Attention to the Agglomeration Effect and Build a Tourism Complex}

Through efficient allocation of regional production factors, full utilization of infrastructure, and active shaping of an innovative environment, industrial agglomeration promotes resource appreciation, information diffusion, knowledge innovation, technological advancement, and efficiency improvement, stimulates local development potential, and enhances regional production capacity. Agglomeration can make existing tourism industries form a linkage, give full play to the vitality of existing industries, and bring greater economic benefits to the region. Through the gathering of various industries such as food, housing, transportation, entertainment, shopping, etc., a tourism complex in Nishan Town will be formed and more comprehensive tourism projects will be developed. At the same time, pay attention to the development of regional tourism, integrate the advantages of scenic spots, and design and launch high-quality, rich-content boutique routes that represent the overall image of Qufu cultural tourism for tourists at home and abroad, centering on "eat, live, travel, travel,

Table 1. SWOT analysis framework of tourism development in Nishan Town.
S-strengths
1) Resource strengths
W-weaknesses
2) Location strength
1) Low quality of workers
3) Transportation strength
2) Difficulty in urban transformation
4) Customer strength
3)Insufficient development
5) Policy strengths

O-opportunities

1) The impact of social activities

2) Socio-economic factors

3) The development of tourism in Shandong Province

T-threats

1) Fierce competition

2) Changes in the trend of the times

3) Homogenization
SO-combination strategy Maximizing internal WO-combination strategy

advantages and seizing external opportunities is Avoiding internal disadvantages and seizing a growth strategy.

Pay attention to the agglomeration effect and build a tourism complex.

\section{ST-combination strategy}

Maximizing internal advantages and avoiding external risks is an avoidant strategy.

Actively expand way of thinking and scientifically plan scenic spots. external opportunities is a torsion strategy.

Keep up with the trend of the times and change the development model.

WT-combination strategy

Overcoming internal disadvantages and avoiding external risks is a defensive strategy.

Improve professional standard and enhance cultivation of talents. 
shopping, and entertainment" to provide service, upgrade the scale and quality of existing hotels, plan to increase a number of high-end, distinctive tourism and entertainment facilities and hotels, increase the stay time of tourists, and expand tourism consumption space, vigorously develop Confucian cultural tourism resources and create a series of tourism products with Qufu characteristics.

Actively strive for funds and technology, and promote the construction of characteristic towns, carry out activities such as village development and protection, construction of tourist facilities, and development of scenic spots. Strictly control illegal and disorderly construction, and promote the improvement of rural environment and the promotion of tourism image. Relocate or renovate old and narrow buildings or plots, improve supporting facilities, and enhance the tourism reception capacity of towns. Speed up the construction of the township ring road, rationally divert the passenger flow during peak periods, and strengthen the creation of a hard environment. Make overall plans for infrastructure such as squares and roads, actively promote the construction of "village revitalization", carry out actions to remediate the rural settlements environment, and create beautiful villages with distinctive characteristics.

\subsubsection{Keep Up with the Trend of the Times and Change the Development Model}

With the rapid development of society and economy, the domestic tourism industry has entered a period of vigorous development, and the people's tourism consumption concept was also changed accordingly, from ordinary sightseeing tourism to more advanced leisure tourism and experiential tourism. Nishan Town should fully use its own advantages and develop entertainment projects based on its own characteristics. Study tours and leisure tours are becoming more and more popular, providing new ideas for the tourism of Nishan Town. In addition, the continuous innovation of science and technology has brought a huge impact to the traditional tourism industry. Nishan Town should actively explore the operation mode of the Internet, break the traditional thinking pattern, change the development mode, and keep up with the trend of the times.

On the one hand, the exploration and development of tourism resources can promote the growth of social economy and culture; on the other hand, it also exacerbates the loss of the environment and the disappearance of local characteristics. The development of tourism must adhere to the protection of tourism resources and appropriate development, and ensure that tourism development and the ecological environment achieve permanent harmony. We must adhere to the concept of sustainable development as the guiding ideology, advocate the sustainable use of resources, and protect and develop carefully. The idea of ecotourism has often been mentioned, and tourist attractions should achieve the sustainable development of tourism resources. Each tourist area has a certain carrying capacity, but blind development beyond the carrying capacity will cause irreversible damage to various tourist resources. Therefore, it is necessary to carry out a scientific calculation of the carrying capacity of the scenic area to 
ensure that the development and use of the scenic area are within the scope of the carrying capacity.

In order to reflect science, forward-looking thinking and operability, it is necessary to adopt modular design concepts to coordinate the layout, correctly handle the relationship between protection and utilization, highlight regional characteristics, avoid similarities and repeated constructions, and ensure the rational exploration, sustainable utilization of resources and sustainable development of industry.

\subsubsection{Actively Expand Way of Thinking and Scientifically Plan Scenic Spots}

Establish the concept of regional tourism and keep up with the pace of Qufu's construction of an international tourist city. To promote further development of tourism in Nishan Town, it is necessary to firmly establish the concept of regional tourism, treat the entire town as a relatively complete tourism product, seek comprehensive benefits in many aspects, promote the common development of tourism objects and tourism subjects, and realize interaction between tourism and culture. In the new era, Nishan Town should make long-term strategic goals, that is, relying on high-quality tourism resources, location and transportation advantages, adopting effective publicity and promotion, conforming to the general trend of cultural tourism and traditional Chinese cultural development, and implementing a regional economic coordinated development strategy, striving to develop the domestic and foreign tourist source markets, which win with the potential of cultural connotation and continuously improve the city's taste, building China's first brand of humanistic tourism, and moving towards an international tourist city. Strengthen the rectification of the tourism environment, with the construction of honest tourism as the core, establish and improve various management systems, improve service concepts, strengthen industry management, rectify the tourism order, purify the tourism environment around the scenic spot, and continuously optimize software and improve hardware, making tourists feel the humanistic care and perfect service of cultural tourism in Nishan Town so as to build a good brand image and tourist destination image. Strengthen the reception service capacity, accelerate the construction of key tourism projects, and develop special tourism projects such as farmhouses and fishermen's homes. On the other hand, it is necessary to develop supporting urban construction projects, infiltrate the concept of regional tourism, and promote the transformation and upgrading of urban accommodation, transportation, shopping, entertainment and other basic service facilities.

Tourism products are an important part of the development of tourism. Local governments should rely on local resources and culture for further development to create a rural tourism product system with high added value and local characteristics. In this process, the cross-border integration of regional tourism should be actively promoted. First, excavate the cultural connotation and value of the times in Qilu, and promote the integration of cultural and artistic indus- 
tries, folk culture and tourism. Next, give full play to the catalytic, integration, synergistic, and radiation effects of the tourism industry, promote the conversion of new and old kinetic energy, and deepen the integration with new industries. Finally, tap the potential of the tourism economy, cultivate and develop conference and exhibition tourism, build a precision marketing and promotion system, and enhance the level of integration of technology, education and tourism. Nishan Town should learn from some effective practices in advanced areas at home and abroad, guide tourist attractions at all levels to develop and innovate multi-level and diverse tourist products that can reflect their own individual culture, gradually make tourism products the main source of economic growth, and strive to develop participatory cultural experience products and extend the stay of tourists to a strategic level to plan and operate so that tourists can increase cultural knowledge and feel the atmosphere and atmosphere of culture during tourism.

At the government level, we must break free, seize opportunities, and focus on building an industrial upgrading perspective, and comprehensively development. When formulating and revising local tourism development plans, the tourism administrative departments at all levels must pay attention to or enrich the content of tourism cultural development. Speed up the transformation of government functions, straighten out the cultural tourism management system, promote the gradual transformation of government administrative departments from office to management, from micro-management to macro-control, and gradually transform the government functions from management to service. The quality of the plan directly affects the sustainable development of rural tourism. The relevant departments should formulate a scientific plan for Nishan Town, including short-term planning and long-term planning, clarify the strategic positioning, build brand effects, and ensure the effective implementation of the plan and the goals. At the same time, the development of rural tourism must do a good job in marketing and publicity to increase brand awareness. In the process of specific implementation, a diversified channel system should be created, including media promotion, network promotion, festival promotion, joint promotion, etc., in order to promote the expansion of the tourism market, expand its influence, and attract more tourists.

\subsubsection{Improve Professional Standard and Enhance Cultivation of Talents}

The consumer population of rural tourism in Nishan Town should be mainly targeted at people with a knowledge and cultural level above junior high school, high family income, pursuit of fresh stimulation, and a strong interest in folk customs, geographical science, and health care. Relying on the rich resources of domestic and foreign tourists in Qufu, travel conditions require both self-driving and group outings.

Practice has proved that the increasingly fierce competition for talents will become a decisive factor in seizing the future commanding heights of the cultural tourism industry. For the cultural tourism industry, among the various human 
resources, the most precious and core resource is the compound cultural management personnel who understand both cultural tourism and management. Governments and cultural management departments at all levels must implement the cultural tourism industry talent training project in a planned and step-by-step manner, and vigorously introduce business management talents and technological innovation talents. It is necessary to cultivate outstanding cultural professionals who are both moral and artistic, but also to cultivate senior compound talents in the cultural industry who are familiar with art, have a high sense of innovation and cultural taste, understand market operations, have high management skills and the ability to act in accordance with the law. Broaden the channels and methods for identifying talents, promote system innovation, fully implement the employment system and appointment system, and improve methods such as competitive employment and public recruitment. It is necessary to create a harmonious environment in which people make the most of their use, form an institutional system for cultivating, retaining and attracting talents, reward cultural talents with outstanding contributions, give top-notch talents preferential treatment, and accumulate human capital for the sustainable development of the cultural industry. High-level professionals are an urgent requirement for the rapid development of the tourism industry, and the comprehensive quality of employees is an important condition for the development of the tourism industry. Nishan Town should adapt to local conditions, formulate a development model that meets the characteristics of the town, and train tourism practitioners in multiple ways and at multiple levels In the development process, innovation and creativity are needed, and it cannot follow the path of homogeneity, which needs to develop their own content and experience services based on the actual situation of Nishan Town, and create an industry scale with a green circular economy as a closed-loop.

\section{Conclusion}

Based on the SWOT analysis of Nishan Town's tourism development, this article shows that Nishan Town has advantages in terms of resources, location, transportation, source of tourists, policies, etc, but low quality of wokers, difficulty in urban transformation, and insufficient development are disadvantages. Although social activities, social economy, and regional tourism have brought opportunities to Nishan Town, at the same time, it also needs to face the challenges of competition, changes in the trend of the times, and homogenization. According to the results of the SWOT analysis, this article puts forward specific suggestions, which are conducive to the more scientific and efficient development of Nishan Town's tourism industry, conform to the changes of the times, clarify its own strategic positioning, promote the employment and improve quality of local residents so as to make contributions to rural revitalization.

\section{Funding}

This work is supported by Social Science Project of Taian (20-YB-001). 


\section{Conflicts of Interest}

The authors declare no conflicts of interest regarding the publication of this paper.

\section{References}

Gan, J., Gao, F., \& Li, B. (2021). Research on Border Tourism Development of Manzhouli City Based on SWOT Analysis. Journal of Jilin Normal University (Natural Science Edition), 42, 130-133.

Kong, Z., \& Zheng, Y. X. (2010). Research on Qufu Cultural Tourism Development Based on SWOT Analysis. Journal of Qingdao Vocational and Technical College of Hotel Management, 2, 40-44.

Li, J. F. (2021). Research on the Development of Rural Tourism in Jin'an Town Based on SWOT Analysis. China Business Review, 1, 54-58.

Li, T., Zhu, H., Wang, Z., Tao, Z. M., \& Tao, H. (2020). Research on the Spatial Agglomeration Characteristics and Structure of Rural Tourism in Southern Jiangsu. Geographical Research, 39, 2281-2294.

Liao, Y. J. (2019). Thoughts on the Development of Rural Tourism Based on International Experience. City, 7, 71-79.

Liu, Y. X., Jia, Z. Z., \& Zhang, K. Q. (2020). Research on Rural Tourism Development of Gaopo Miao Nationality Township in Guiyang City Based on SWOT Analysis. Rural Economy and Technology, 31, 68-70.

Liu, Y. Z. (2020). Research on the Globalization Development Path of Rural Tourism in Shandong Province Based on SWOT Analysis. Management and Technology of Small and Medium-Sized Enterprises (Mid-Term Journal), 8, 63-65. 